Para enlazar con este artículo / To link to this article:

http://dx.doi.org/10.14198/fem.2019.33.06

Para citar este artículo / To cite this article:

Ahedo Gurrutxaga, Igor y Ureta García, Miriam. «Desvelando opresiones y resistencias de las mujeres en Zumarraga (País Vasco): un análisis interseccional para profundizar la democracia participativa en términos de justicia social». En Feminismo/s, 33 (junio 2019): 145-169. Dosier monográfico: Diálogos entre la democracia participativa y la interseccionalidad. Construyendo marcos para la justicia social, coords. Patricia Martínez-García y Jone Martínez-Palacios, DOI: 10.14198/fem.2019.33.06

\title{
DESVELANDO OPRESIONES Y RESISTENCIAS DE LAS MUJERES EN ZUMARRAGA (PAÍS VASCO): UN ANÁLISIS INTERSECCIONAL PARA PROFUNDIZAR LA DEMOCRACIA PARTICIPATIVA EN TÉRMINOS DE JUSTICIA SOCIAL ${ }^{1}$
}

\author{
UNVEILING OPRESSIONS AND RESISTANCES OF \\ WOMEN IN ZUMARRAGA (BASQUE COUNTRY): \\ AN INTERSECTIONAL ANALYSIS IN ORDER TO DEEPEN \\ PARTICIPATORY DEMOCRACY IN TERMS OF SOCIAL \\ JUSTICE
}

\author{
Igor AHEDO GURRUTXAGA \\ Universidad del País Vasco \\ igor.ahedo@ehu.eus \\ orcid.org/0000-0002-6341-3342 \\ Miriam URETA GARCÍA \\ Universidad del País Vasco \\ miriam.ureta@ehu.eus \\ orcid.org/0000-0002-8466-4327
}

\footnotetext{
1. Esta investigación ha sido financiada por el Ayuntamiento de Zumarraga (Guipúzcoa, País Vasco). (CC BY 4.0)
} 
Desvelando opresiones y resistencias de las mujeres en Zumarraga (País Vasco): un análisis interseccional para profundizar la democracia participativa en términos de justicia social

\title{
Resumen
}

La presente investigación persigue alcanzar tres objetivos: (i) desvelar cómo diferentes mujeres están atravesadas por entrecruzados ejes de opresión de género, clase, raza, edad y/o movilidad en un contexto de desmantelamiento industrial y de expulsiones en el mercado de trabajo asalariado en Zumarraga (País Vasco); (ii) visibilizar sus formas de resistencia y (iii) un tercer objetivo de carácter más normativo que busca desactivar situaciones de vulnerabilidad. Para ello, el estudio hará uso de las potencialidades heurísticas que ofrecen los marcos propuestos por Patricia Hill Collins la «matriz de dominación», los «ámbitos de poder» y las «políticas de comunidad» planteados de forma articulada como herramienta de análisis interseccional aplicado. Bajo este enfoque, se han puesto en diálogo las experiencias vivenciales de 37 vecinas y vecinos de Zumarraga y los resultados de dos talleres participativos con mujeres, orientados a activar sus demandas en aras de profundizar la democracia participativa en términos de justicia social.

Palabras clave: Interseccionalidad, profundización democrática, justicia social, Zumarraga.

\begin{abstract}
This research aims to reach three goals: (i) unveiling how different women are traversed by intersecting axes of oppression -gender, class, race, age and functional diversity in a context of industrial dismantling and expulsions from the labor market in Zumarraga (Basque Country); (ii) make visible their ways of resistance and (iii) a third objective of a more normative nature which seeks to deactivate situations of vulnerability. In doing so, the study will make use of the heuristic potential offered by the frameworks proposed by Patricia Hill Collins the «matrix of domination», the «domains-of-power» and the "politics of community» articulated as an applied tool of intersectional analysis. Thus, the experiences of 37 residents of Zumarraga and two paticipatory groups have been put in dialogue, both oriented to the activation of their demands to deepen participatory democracy in order to achieve social justice.
\end{abstract}

Keywords: Intersectionality, democratic deepening, social justice, Zumarraga.

\section{INTRODUCCIÓN}

Asumir un análisis interseccional implica comprender cómo diferentes mujeres experimentan la opresión teniendo en cuenta la heterogeneidad de sus vivencias a la luz de sistemas de poder que se entrecruzan como una maraña en base al género, clase, raza, edad y/o movilidad. La noción hunde sus raíces

Feminismo/s 33, junio 2019, pp. 145-169 
Desvelando opresiones y resistencias de las mujeres en Zumarraga (País Vasco): un análisis interseccional para profundizar la democracia participativa en términos de justicia social

en los feminismos negros, cuando Kimberlé Crenshaw nombró la interseccionalidad como perspectiva analítica (140), para alumbrar la manera en que diversas mujeres estaban atravesadas por el cruce de caminos que representan los ejes de opresión de género y raza. Sin perder su carácter radical y originario, teórico-activistas del Black Feminism fueron madurando esta idea hasta que Patricia Hill Collins designó la interseccionalidad como paradigma para explicar las experiencias multidimensionales de las Mujeres Afroamericanas y cómo éstas encarnaban las diferentes estructuras de opresión en sus narrativas vivenciales (Black Feminist Thought 221-238). Sin embargo, subsiguientes lecturas revisionistas han venido a cooptar la idea genuina de la interseccionalidad procediendo a su «blanqueamiento» (Bilge 412).

A pesar de estos «malos viajes» (Martínez-Palacios y Martínez-García 7) y de los intentos por situar sus aportaciones «al servicio de agendas neoliberales» (Collins y Bilge 63-87), nuevas contribuciones que repolitizan la idea de interseccionalidad (Gandarias 83) y que son respetuosas con su genealogía apuntan hacia un diálogo fructífero con las ideas de «democracia participativa» $y$ «justicia social». Es en este sentido en el que la interseccionalidad recupera su radicalidad como paradigma y herramienta analítica cuyo potencial heurístico es fundamental para entender cómo los sistemas de opresión se entretejen en procesos de profundización democrática, afrontando la interseccionalidad «el reto de crear un mundo más inclusivo» (Collins y Bilge 4) en términos de justicia social.

En esta línea, Pedro Ibarra desarrolla un acercamiento normativo a la democracia asentado en la coherencia entre las expectativas del demos y la deliberación en las instituciones; donde esta debe combinar avances en cuatro esferas además de la representativa: la comunicativa, la de la movilización, la de la gobernanza y la de la participación ciudadana (38). Así, habida cuenta de que el núcleo central de las estrategias participativas es la vertebración de dolores (Ganuza, Olivari y Paño 136) transitando del «qué hay de lo mío» al «qué hay de lo nuestro», las perspectivas de la «democracia participativa» apuntan «hacia aquellas áreas oscuras en las que las demandas de determinados grupos y/o personas necesitan ser alumbradas» (Pérez de la Merced 151). Esta cuestión requiere de un acercamiento que entienda que la participación no solo tiene clase o color de piel, sino también género (MartínezPalacios, ¿Qué significa participar? 371); donde es precisamente la idea de

Feminismo/s 33, junio 2019, pp. 145-169 
Desvelando opresiones y resistencias de las mujeres en Zumarraga (País Vasco): un análisis interseccional para profundizar la democracia participativa en términos de justicia social

interseccionalidad la que permite avanzar en el proceso de «visibilización» de realidades complejas (Martínez-Palacios y Martínez-García 9).

Finalmente, la tercera pieza de la tríada se asienta en el horizonte de la justicia social, que se interpreta en las claves definidas por Nancy Fraser en términos de complementariedad (Iglesias 253) entre las lógicas de redistribución, reconocimiento y representación. Por tanto, «interseccionalidad», «democracia participativa» $\mathrm{y}$ «justicia social» establecen sinergias transformadoras al permitir pensar y hacer política reconociendo la multiplicidad y pluralidad de experiencias vivenciales de mujeres y, así, posibilitar el desarrollo de diseños participativos que sean inclusivos y justos de acuerdo a los ejes de opresión que las atraviesan (Lombardo y Rolandsen 21).

\section{ONTOLOGÍA DEL PODER DUAL Y STANDPOINT THEORY}

Más aún, la relación entre las nociones de «interseccionalidad», «democracia participativa» $\mathrm{y}$ «justicia social» se puede explorar examinando las luchas de resistencia de los grupos tradicionalmente oprimidos (Collins, The Difference that Power Makes 22) ya que la ontología del poder de la interseccionalidad asume una correspondencia entre la opresión y la resistencia (Baca Zinn y Dill 328-329). Esto es, la interseccionalidad comprende una ontología del poder según la cual este es tanto opresivo como empoderante (Dhamoon 239), rechazando posturas que reducen el «poder político al ejercicio de la opresión y que localizan el poder exclusivamente en aquellos grupos privilegiados» (Severs, Celis y Erzeel 42). Se rehúyen así lógicas unidireccionales top-down disolviendo «la rígida distinción entre poderosos y quienes carecen de poder» (Squires 36 citado en Severs, Celis y Erzeel 42), donde este se entiende dentro de una complejidad dinámica en la que se producen situaciones simultáneas de opresiones y resistencias que consideran «el impacto correlativo de estructura y agencia» (Archer 190).

Esta interacción permite comprender cómo se encarnan las opresiones y resistencias en las experiencias humanas desde diferentes posiciones (Collins y Bilge 25-30). Por tanto, este planteamiento ontológico del poder establece fuertes sinergias con la epistemología feminista del punto de vista-standpoint theory- la cual mantiene que aquellas personas que se encuentran marginadas con respecto a los centros de poder tienen una visión mucho más precisa de

Feminismo/s 33, junio 2019, pp. 145-169 
Desvelando opresiones y resistencias de las mujeres en Zumarraga (País Vasco): un análisis interseccional para profundizar la democracia participativa en términos de justicia social

las formas en las que el poder se expresa y se impone sobre ellas (Guzmán y Pérez 116), generando narrativas más libres de los sesgos producidos por visiones sexistas, clasistas o racistas (Collins, Black Feminist Thought 221228) y «situando en el centro las experiencias de quienes sufren la exclusión» (Martínez-Palacios, Democratizing Participation through Feminism 44).

\section{ANÁLISIS CONTINGENTE: ZUMARRAGA (PAÍS VASCO)}

Partir de una comprensión ontológica del poder dual y de la epistemología feminista del punto de vista implica tomar en consideración las «percepciones de problemas estructurales que reflejan cómo actores sociales están situados dentro de las relaciones de poder en contextos históricos particulares» (Collins, Black Feminist Thought 20). Por tanto, abordar la interseccionalidad respetando su genealogía significa huir de planteamientos universalizantes y trabajar a partir de situaciones contingentes.

Así, el contexto específico de este trabajo se circunscribe a Zumarraga (Gipuzkoa, País Vasco), localidad de 9.868 habitantes, de los cuales el 51,06\% habla euskera, el 24,31\% tiene más de 65 años, el 10,77\% tiene estudios superiores y un 7,83\% nació en el extranjero, según los datos aportados por el Instituto Vasco de Estadística (Eustat). La población de Zumarraga se encuentra en un momento clave para su futuro, marcado por el final de una etapa durante la cual se articuló la identidad y la vertebración comunitaria en torno a la industria; ya que desde el final de la Guerra Civil tomó preponderancia la recién instalada factoría Esteban Orbegozo -posteriormente Arcelor Mittal- dedicada a la siderometalurgia que ha venido a atraer desde los años 50 a oleadas de trabajadores provenientes de otras regiones del Estado español, disparando la población de Zumarraga hasta su cierre.

La clausura de la empresa industrial anunciada a partir de 2016 vino a amenazar 350 empleos directos y 200 puestos de trabajo indirectos; donde 209 trabajadores optaron por la carta de despido, otros 70 han venido a participar en itinerarios formativos ofrecidos por instituciones públicas, 85 se decantaron por las reubicaciones y 21 de estas personas fueron prejubiladas. Este proceso de desmantelamiento industrial pone la «guinda» a la destrucción paulatina del empleo industrial que no se ha visto sustituido por la generación de nuevos nichos económicos tractores a nivel laboral. 
Desvelando opresiones y resistencias de las mujeres en Zumarraga (País Vasco): un análisis interseccional para profundizar la democracia participativa en términos de justicia social

Como consecuencia, la tasa de paro en Zumarraga es del 14,4\%, casi cinco puntos porcentuales por encima de la media del País Vasco (10,2\%); lo cual tiene impacto directo en la vida de sus habitantes, pues el PIB per cápita -un buen indicador de la calidad de vida- se sitúa actualmente en Zumarraga en 23.357,5 euros; casi diez mil euros por debajo del PIB medio per cápita en el País Vasco, que es de 33.088 euros.

Estos datos han hecho germinar una serie de corrientes subterráneas que sitúan la mirada en miedo respecto de las limitaciones económicas del presente e incertidumbre con respecto al futuro. Amenaza que impacta muy especialmente en los sectores vulnerables, para quienes se intensifican los ejes de opresión en este contexto de reestructuración:

En el pueblo hay una sensación de miedo de ¿Qué va a pasar con Zumarraga? Estamos todos un poco escondidos. Ahora está todo el mundo muy a la expectativa. Al que le ha tocado de cerca, porque su marido o su mujer trabajaba en Arcelor, y al que no también, porque me puede pasar mañana a mí.

Un marco de urgencia con consecuencias sobre las mujeres del municipio:

La falta de trabajo puede traer problemas entre la gente [...] Al final: mi marido trabajaba ahí y ganaba bien, yo he trabajado no sé dónde, mi marido está en casa, quito la chica que estaba cuidándome a los niños, la chica se va al paro. Esa chica que no tenía una formación y ahora qué va hacer... Yo a la ama le mandaba al centro de día porque trabajábamos, ahora saco del centro porque la cuidamos en casa. Es una reestructuración.

\section{PLANTEAMIENTO METODOLÓGICO}

En este contexto, la administración municipal y el equipo de investigación negocian la puesta en marcha de un proceso desde la perspectiva metodológica de la Investigación-Acción-Participativa (IAP) de doble apertura y cierre: se definen los objetivos y se elabora un diagnóstico de vulnerabilidades con perspectiva interseccional realizado en 2018 a partir de la propia praxis participativa (Martí 79) y en función del/la: género, situación socioeconómica, raza, edad, nivel educativo, localización geo-espacial (rural/urbano), diversidad funcional, identidad nacional, conocimiento de las lenguas oficiales de la Comunidad Autónoma Vasca (CAV) y orientación sexual.

Tras la elaboración de la cartografía, se realizan 13 entrevistas en profundidad a informantes clave del espacio asociativo, asistencial, técnico, político,

Feminismo/s 33, junio 2019, pp. 145-169 
Desvelando opresiones y resistencias de las mujeres en Zumarraga (País Vasco): un análisis interseccional para profundizar la democracia participativa en términos de justicia social

sindical y educativo identificados previamente por un grupo motor configurado por una representación del cuerpo técnico y de toda la corporación política. Las entrevistas realizadas permiten identificar los cruces de vulnerabilidades que los agentes locales destacan como más relevantes. Así, se inicia una búsqueda de personas del municipio que responden a uno o más cruces preponderantes; donde se localizan 24 personas atravesadas por una interseccionalidad de opresiones salientes. De forma encadenada se entrevistan en total 17 mujeres en función de la caracterización de perfiles que encarnan la soledad, la maternidad, la orientación sexual, su papel de cuidadoras de personas dependientes, la edad, raza, religión y diversidad funcional.

Tras la fase de apertura, se inicia una etapa de cierre que se materializa en dos talleres que buscan concretar líneas de actuación donde los sectores implicados asumen un papel protagonista en el desarrollo del proceso (Martí 79). A tal efecto se lanza una convocatoria semicerrada siguiendo la técnica de muestreo de la bola de nieve o cadena (Martínez-Salgado 616), facilitado este proceso por la flexibilidad del diseño de la investigación en la IAP. En el primero de los talleres se acuerda un diagnóstico compartido sobre las consecuencias de la crisis económica sobre las mujeres; el segundo sirve de transición a una nueva etapa en marcha en la actualidad de identificación de alternativas, que se está concretando en 2019 con el diseño de estrategias participativas orientadas a avanzar en la justicia social a partir del desarrollo de propuestas asociadas al cuidado comunitario, asumidas como necesarias tanto por la población vascoparlante de orientación política y cultural ligada al nacionalismo como por las pertenecientes a familias emigrantes del periodo industrial, más vinculadas al socialismo.

Así, la puesta en marcha de estas actuaciones abre un nuevo ciclo en el que se detectarán nuevos síntomas y problemáticas, y en el que cabrá definir nuevos objetivos a abordar (Martí 1). En esta línea, el desarrollo comunitario por el que apuestan las metodologías participativas que se están activando en 2019 aplicando las recomendaciones de la investigación puede alinearse tanto con la memoria colectiva del auzolan estrategias de apoyo como con la del movimiento vecinal. Por tanto, se apuesta por una estrategia que sortea los imaginarios de dos comunidades que históricamente han mantenido relaciones conflictivas, superadas sobre todo con la inserción de sus descendientes en una escuela vasco-parlante que cierra con la infancia las heridas del pasado,

Feminismo/s 33, junio 2019, pp. 145-169 
Desvelando opresiones y resistencias de las mujeres en Zumarraga (País Vasco): un análisis interseccional para profundizar la democracia participativa en términos de justicia social

y que -como se verá- sirva ahora también de espacio privilegiado para coser una comunidad que mira con cierta distancia a los nuevos emigrantes globales del siglo XXI.

\section{APLICAR UN ANÁLISIS INTERSECCIONAL EN ZUMARRAGA}

Así, con la mirada fijada en Zumarraga y orientada a la consecución de los tres objetivos de este estudio, se procede a aplicar un análisis interseccional asumiendo la aportación de Hill Collins, quien propone estructurar tres marcos de forma encadenada: la «matriz de dominación», los «ámbitos de poder»y las «políticas de comunidad» (The Difference that Power Makes 22-28).

\subsection{Matriz de dominación}

La orientación matricial que la presente investigación toma como punto de partida implica llevar a cabo «un estudio de saliencia esencial para todo análisis interseccional» (Collins, The Difference that Power Makes 25), pues no todos los sistemas de poder son análogos. Por tanto, esta investigación identifica cómo se construye la matriz de dominación en Zumarraga, en donde las opresiones por razón de género, clase, raza, edad y movilidad se entrecruzan de forma dinámica para configurar una red de poder prominente. Partir de la visibilización del particular «cruce de caminos» de determinados sistemas de poder relevantes actuantes a nivel local ayuda desde el principio a elevar el foco y conocer la forma en que fenómenos dinámicos de resistencia se expresan.

\subsection{Los «ámbitos de poder»}

Es a partir de la matriz de dominación cuando se desciende al nivel de análisis del marco de «ámbitos de poder», el cual proporciona un conjunto de herramientas teóricas afinadas que ayudan a concretizar cómo los ejes de poder se entrecruzan sobresaliendo de forma particular en Zumarraga de forma coherente con la matriz de dominación en la que se ubica. Esta operación permitirá aspirar a alcanzar el primer objetivo de la investigación: desvelar cómo diferentes mujeres se encuentran atravesadas por los ejes de opresión de género, clase, raza, edad y/o diversidad funcional en Zumarraga. 
Desvelando opresiones y resistencias de las mujeres en Zumarraga (País Vasco): un análisis interseccional para profundizar la democracia participativa en términos de justicia social

Así, el marco de los «ámbitos de poder» despliega su potencial analítico a través de cuatro elementos fundamentales, iluminando formas complejas de dominación y resistencia (Collins, The Difference that Power Makes 54-56) desde la construcción interrelacional de elementos estructurales, disciplinarios, culturales e interpersonales.

Así, el primer «ámbito de poder» es (i) el del poder estructural, aquel en el cual se regulan las políticas públicas que organizan las instituciones a partir de las cuales las jerarquías sociales toman forma (Collins, The Difference that Power Makes 26); donde este trabajo asume que las políticas públicas no sólo se deben ligar a la actuación de los poderes públicos, sino a los procesos de no-decisión (Dye 3) y sus causas (Platero, López y Peterson 162), siendo todo aquello que los gobiernos deciden hacer o no hacer (Walt 41). De esta definición se deriva la posibilidad de que las instituciones políticas puedan llevar a cabo acciones deliberadas de no actuación (Hoogwood y Gunn 21).

Es por ello por lo que la complejidad del análisis interseccional permite alumbrar estas posibles formas de ejercicio de poder y de opresiones/resistencias. Complementariamente, la idea de ámbito de poder estructural y de políticas públicas está estrechamente relacionada con la capacidad de acceso al espacio público deliberativo oficial por parte de distintos grupos sociales, pudiendo producirse una exclusión/expulsión de ese espacio del conjunto de subjetividades y prácticas de los grupos que representan la diferencia (Young 250-251) y se encuentran subordinados (Zugaza 205-206).

Así, uno de los problemas de las mujeres que viven de forma más intensa las consecuencias de la crisis multidimensional en Zumarraga es su dificultad de acceso al espacio público-institucional, lo que deriva en desequilibrios en las relaciones de poder que los colectivos de mujeres más afectadas por la crisis experimentan: quedan marginadas de las redes de participación oficial, conllevando ese aislamiento en algunos casos a su no inclusión como voz que arroja luz a la resolución de sus problemas concretos «quedando silenciadas las perspectivas de las personas más afectadas por los problemas sociales» (Collins, The Difference that Power Makes 23). Una realidad que en ocasiones raya el aislamiento de forma fácilmente detectable en el espacio escolar, como refleja este fragmento de una de las educadoras de Zumarraga; ejemplo de la importancia de estructuras de concertación y participación para que estos diagnósticos sean incorporados por las instituciones.

Feminismo/s 33, junio 2019, pp. 145-169 
Desvelando opresiones y resistencias de las mujeres en Zumarraga (País Vasco): un análisis interseccional para profundizar la democracia participativa en términos de justicia social

Hace poco me vino una rumana con dos niños. Nunca me olvidaré, la niña tenía 7 años, el niño 5. [...] Me vienen con una factura, derivada de los servicios sociales. El niño, con una cara de tristeza... La niña transmitía más por los ojos. Al día siguiente la señora volvió y ya le vi que no estaba bien... Pero claro, no tenía los recursos como para saber qué era exactamente lo que le pasaba: ¿Y han ido los niños a la escuela? Sí, lo que pasa es que cogen muchos catarros, la casa en que vivimos tiene mucha humedad, suelen estar enfermos... Muchas veces no van a clase.

En un contexto de falta de empleo y recursos sociales en el municipio, las mujeres trabajadoras se encuentran con un mercado laboral que las arroja de forma creciente y agudizada al ámbito privado: soportan jornadas de trabajo asalariado precario y feminizado, en muchos casos sin cotizar en la seguridad social y, por tanto, sin derecho a posibilidad de prestaciones por desempleo. De esta forma, se redobla la carga de quienes tienen que compatibilizar el acceso al mercado de trabajo con los cuidados. Pero, también, aumenta la vulnerabilidad de quienes se ven expulsadas del mercado de trabajo, en un municipio en el cual este ha sido un elemento de estatus. Como señala una participante:

Para que una mujer sea valorada en la comunidad necesita tener un empleo ya que si se dedica plenamente a ser ama de casa es sometida a una gran presión social de una comunidad que entiende que no es un trabajo real ese vives como una reina si no es remunerado. Por ello, tener un empleo afecta a la propia autoestima.

A esta cuestión se añade que las tareas de cuidados que las mantienen progresivamente cautivas de forma intensificada en el «ámbito doméstico» generan sentimientos de frustración e incertidumbre, a lo que se suma una serie de «malestares»y «sufrimientos» producidos por conflictos por el tiempo e imposibilidad de integrarse en la vida social del municipio como consecuencia de largas jornadas de trabajo. Así lo expresa una de las participantes: «El sector está tan precarizado que, en muchas ocasiones, estas mujeres trabajan sin cotizar en la seguridad social, con salarios muy bajos y jornadas laborales infinitas. Hace poco, la prensa hablaba de las internas como las nuevas esclavas de Gipuzkoa». Especialmente grave es el caso de las mujeres trabajadoras racializadas, para quienes según sus narrativas los trabajos de cuidados son casi su única opción de subsistencia en el mercado laboral, produciéndose 
Desvelando opresiones y resistencias de las mujeres en Zumarraga (País Vasco): un análisis interseccional para profundizar la democracia participativa en términos de justicia social

además una paradoja: asumir este tipo de trabajos para poder alcanzar un sueldo mínimo, mientras no pueden a dedicar espacios/tiempo a labores reproductivas y de crianza de sus propios hijos/as.

Para empezar trabajan 22 horas al día ¿Dime cómo se relacionan con el pueblo? Están 22 horas trabajando con una familia viviendo, duermen con el anciano con el que están viviendo, no duermen bien y tal, ya me dirás tú cómo una persona que duerme dos horas al día puede relacionarse.

Unas restricciones que se entrecruzan con los obstáculos propios de ser migrantes: dificultades lingüísticas, situaciones de excepcionalidad por no haber tenido la ciudadanía legal o no haber contado con el apoyo afectivo que supone la presencia de su familia. Toda esta maraña de opresiones que mantiene a estas mujeres «encadenadas» a/por trabajos de cuidados que entrañan duras jornadas, de nuevo, genera progresivas exclusiones/expulsiones del espacio público oficial, dificultando que se reflejen sus experiencias en el diseño e implementación de las políticas públicas y promoviendo el cierre absoluto a otro tipo de trabajo:

Cuando eres diferente se hace aún más complicada la búsqueda de empleo. Cultura, diversidad funcional, género, etnia, origen, religión... Cada uno de los ejes hace que las personas tengan que demostrar la valía más y más de cara a la sociedad. Y eso impacta directamente en el bienestar. Evidentemente, el uso del hiyab cierra puertas para trabajar cara al público.

En el caso de las mujeres de avanzada edad, estas quedan «atrapadas» en el ámbito privado, sometidas en muchos casos a sentimientos de vergüenza al no poder hacer frente a facturas de productos y servicios básicos, lo que las lleva a ocultar sus vivencias, a no socializarse y a «esconder debajo de la alfombra» problemas que valoran como «personales», pero que están atravesados por estructuras de opresión en base al género, clase y edad. A esta realidad específica hay que sumar el hecho de que muchas de estas mujeres tienen problemas de salud o de movilidad, ya que algunas especialmente las que no viven cerca del centro encuentran en las distancias urbanas una barrera física y simbólica añadida que las aleja de las instituciones. El diagnóstico que realiza una de las participantes que regenta una farmacia es preocupante: «Está convirtiéndose este pueblo en un pueblo muy mayor. La clientela cada vez es más anciana, polimedicada». 
Desvelando opresiones y resistencias de las mujeres en Zumarraga (País Vasco): un análisis interseccional para profundizar la democracia participativa en términos de justicia social

Además, muchas de ellas ni contemplan ni se ven capaces de abrir la puerta a personas conocidas o pedir ayuda a los servicios sociales, debido a sentimientos de autoculpabilización y frustración que devienen en una auténtica prisión para mujeres retraídas en el ámbito privado, sin que sus realidades puedan ser iluminadas en el espacio público oficial y tenidas en cuenta por las administraciones públicas. Así las cosas, la preocupación por la salud de las personas mayores es central en este municipio, y se vincula con la crisis de los cuidados y sus consecuencias sobre las mujeres:

Zumarraga es de las poblaciones más envejecidas de Gipuzkoa y por supuesto de la Comunidad Autónoma. Entonces eso se nota ¿Quién les cuida? Antes las propias familias cuidaban a la gente de aquí. Pero entiendes que no, y la gente de aquí difícilmente se dedica a eso. Se contrata a una persona que duerme ahí la noche. A estas personas les explotamos, pues sí, les explotamos. Lo mismo que hubo explotación con los de aquí, exactamente igual.

Asimismo, con respecto de las mujeres con diversidad funcional hay una incomprensión de sus capacidades y una falta de voluntad política que se traduzca en decisiones públicas para su integración efectiva en la vida del municipio, donde no hay estructuras de movilidad adaptadas en diferentes espacios vivenciales necesarios para la convivencia, tales como infraestructuras -parques, polideportivo-; -transportes u otros servicios- -aseos en determinados puntos estratégicos-. Así, el marco de poder estructural se despliega a través de ausencia de decisiones políticas que invisibilizan las realidades de mujeres con diversidad funcional.

Yo salgo de mi casa y todos los días me tengo que plantear por dónde voy a ir y por dónde voy a volver. Y soy una persona muy activa $[\ldots]_{i}$ Me puedes decir cuándo me vas a garantizar que voy a poder salir un día de casa y voy a andar por las aceras sin tener que pedir permiso al resto de los ciudadanos para vivir? Sólo tengo una vida, a mí no me vale que mañana. Y la vida se me está acabando, y no tengo ganas de vivirla a medias porque vosotros decidís que no hacéis lo que tenéis que hacer.

No se nos considera individuos de pleno derecho. Aunque se nos da la razón. El otro día mismo le dije a un diputado: A ver, yo tengo el saco de atrás lleno de derechos, yo quiero que me digas cómo se hacen útiles esos derechos luego. Tengo un saco todo lleno de razones, me salen por todos lados las razones, pero no me ayudan ni ostias a vivir.

Feminismo/s 33, junio 2019, pp. 145-169 
Desvelando opresiones y resistencias de las mujeres en Zumarraga (País Vasco): un análisis interseccional para profundizar la democracia participativa en términos de justicia social

La exclusión/expulsión de todas estas mujeres del espacio público deliberativo en donde se identifican los problemas sociales y se da voz a la ciudadanía tiene como consecuencia el desencadenamiento de lógicas de incomprensión y estigmatización hacia estos colectivos, reproduciendo así un ambiente cargado de violencia simbólica (Bourdieu 12) que obstaculiza y dificulta la integración y -por tanto- la convivencia.

El segundo elemento del marco de «ámbitos de poder» analiza (ii) el del poder disciplinario, cuando las personas utilizan las normas y regulaciones de cada día y las políticas públicas para apoyar una determinada jerarquía social o desafiarla: «Este ámbito es dependiente en tácticas de vigilancia, las personas se vigilan unas a otras y también actúan como autocensoras» (Collins, The Difference that Power Makes 26).

Un ámbito de poder disciplinario que como reflejaba una cita anterior cristaliza en colectivos de mujeres en situación de desempleo cuyo perfil es de baja cualificación, un sector que representa alrededor de 300 mujeres en Zumarraga. Este grupo se ha visto sometido a miedos, incertidumbres y sentimientos de fracaso que se materializan en una autopercepción negativa sobre ellas mismas y sus expectativas de futuro, lo que implica procesos de (auto)censura y vigilancia con respecto a otras mujeres en un contexto de competencia mutua por recursos escasos -empleo y ayudas sociales-.

Una competencia que se amplifica para las mujeres trabajadoras racializadas «diferentes por su origen», configurando una construcción discursiva de «las otras» sobre las que recae cierta sospecha, ya que se acusa a este colectivo de recibir más ayudas sociales porque se le presupone un mayor número de hijas e hijos; reproduciéndose el estereotipo de género que señala a estas mujeres como cuidadoras naturales. En este sentido, el control y vigilancia con respecto a las mujeres racializadas es especialmente acentuado, reproduciéndose el poder disciplinario en varias circunstancias interconectadas, todas ellas basadas en el «prejuicio». Así, una de las participantes narra su experiencia en el ámbito de la escuela, en la que sus expectativas de integración y colaboración con otras familias se ven frustradas:

Queremos integrarnos pero hay algunas personas que no te dejan integrar. No te dejan, la verdad. Me ha pasado en el cole: el rechazo. Yo me sentí rechazada. Me apunté para partir los bocadillos de pan, y cuando llego me dicen: No, no, ya está, que nosotros estamos suficientes. Y yo pienso A ver, 
Desvelando opresiones y resistencias de las mujeres en Zumarraga (País Vasco): un análisis interseccional para profundizar la democracia participativa en términos de justicia social

\begin{abstract}
¿Por qué el cole me manda un papel para ayudar si vosotros ya estáis...? Dices: Mira, ya me han rechazado y ahora no me apunto más. No tengo ganas, ese es el problema de integrar. Pues tú deja a la gente que se integre. La verdad que ese momento me he sentido muy mal.
\end{abstract}

Un cierre comunitario sobre ciertos colectivos visible también en las narraciones de una mujer gitana que se justifica desde una lógica de responsabilidad ciudadana no delinquir, no autoexcluirse y desde un discurso progresista la defensa de los derechos de las mujeres musulmanas, que hace más fácil digerir el exclusión comunitaria porque elude su asociación directa con la xenofobia y el racismo. Sin embargo, las mujeres racializadas rechazan esta doble moral que permite que la xenofobia se legitime desde argumentos progresistas: bien sean los de la igualdad de género; donde paradójicamente las personas que explicitan su rechazo al velo no vuelven a mencionar nunca más cuestiones de género o el laicismo, criticado como una impostura ya que las tradiciones locales tienen una vinculación estrecha con lo religioso

Se creen que soy sumisa y que mi marido me tiene controlada como un títere, no entienden que yo hago mis cosas por mi relación con Dios, como lo hacen las monjas con su relación con Dios. A las monjas las respetan, se cubren y las respetan. Y ellas lo hacen por fe, y nosotras lo hacemos porque nos pegan si nos los quitamos, y somos unas oprimidas por nuestros maridos ¡No tenemos dignidad!

España está declarado país laico, la escuela es pública pero se celebra Santa Águeda, Santa Lucía. [... . Sólo hacen fiestas católicas. Eso en la escuela pública en el País Vasco ¡Que se celebren todas o que no celebren ninguna! ¿Por qué nuestros hijos no pueden tener la imagen de un cordero para pintar?

El poder disciplinario no sólo «vigila» la perpetuación de los estereotipos de mujeres cuidadoras y receptoras de ayudas, sino que promueve procesos de «(auto)censura» $\mathrm{y}$ «(auto)vigilancia» y por tanto la imposibilidad de integración de muchas de ellas, un análisis que capta la violencia simbólica (Bourdieu 12) que el poder disciplinario despliega sobre las mismas. Asimismo y como ya se ha mencionado con anterioridad, algunas mujeres están marcadas por procesos de autoculpabilización; algo que se expresa de forma clara en el espacio del cuidado a la dependencia que practican algunas mujeres educadas en la identificación de la feminidad con la entrega y abnegación: 
Desvelando opresiones y resistencias de las mujeres en Zumarraga (País Vasco): un análisis interseccional para profundizar la democracia participativa en términos de justicia social

Mi madre no quiere llevarle (al hijo con problemas) a ningún sitio. Para ella es como abandonar a su hijo, y no le metes en la cabeza otra cosa. Yo: A ver ama, no es abandonarlo, es dejarlo para que tú estés tranquila también, por ejemplo, una semana o cuatro días. $O$ un fin de semana. Y nada, que no. Pues bueno, es decisión de ella y ya está. Y mientras ella pueda y ella mande es lo que hay.

Las prácticas disciplinarias que incorporan también apuntan hacia la evitación de los diagnósticos de su situación y cierta oposición a pedir ayuda o ser «ayudadas», incluso en algún caso hay mujeres mayores que se esconden para recibir bolsa(s) de alimentos o pedir el pago puntual de la factura del gas, como narra con dureza una voluntaria de Cáritas:

Te vienen con vergüenza, acercándose con miedo, con su factura de la luz: ¿Me podéis ayudar a pagar la factura de la luz? Dices, esta mujer que tiene una pensión ridícula te empieza a contar y dices: ¿Cómo lo haces? Que vas a su casa y dices: Pero, ¿No pones la tele? No, es que gasta mucho, paso el día mirando por la ventana. Y estoy segura de que no sabemos ni un $20 \%$ de las situaciones que hay aquí.

La ocultación de «miserias» y realidades escondidas herméticamente en el ámbito privado hacen que el acceso a este colectivo sea casi imposible incluso para la propia familia. Algunas de estas mujeres ni siquiera contemplan compartir estas vivencias con sus hijas e hijos incluso si estas y estos tienen cierta comodidad económica bajo el argumento de «no preocuparlas y preocuparlos», ni aún en los casos de que estos/as últimos puedan ayudarlas.

Por su parte, si el poder disciplinario se despliega de forma más aguda sobre un colectivo, este es el de mujeres con diversidad funcional. La inaceptación de sus realidades y, por lo tanto, la permanencia de las barreras materiales y simbólicas que afrontan cada día, están profundamente permeadas en una comunidad censora, manifestando estas mujeres relatos muy duros que desafían esas normas disciplinarias que se imponen con fuerza sobre las mismas. Estas mujeres asumen que no caben en «la norma»y, por tanto, no son leídas como «parte de», sino como «ajenas a», lo que supone una expulsión material y simbólica de las mismas al quedar fuera de la definición de quien/es conforma(n) la comunidad. Algo que es contestado por una de las participantes que analiza su movilidad reducida desde una perspectiva profundamente política:

Feminismo/s 33, junio 2019, pp. 145-169 
Desvelando opresiones y resistencias de las mujeres en Zumarraga (País Vasco): un análisis interseccional para profundizar la democracia participativa en términos de justicia social

Parece que somos un meteorito. En un rincón a esconder y a tratar bien, que no haga ruido y que no caliente mucho [...] es que hay gente que te dice: Total, por ti sólo... iQue no se te olvide que yo sólo tengo el derecho, los mismos que los tuyos! Yo sola.

Además, según se desprenden de sus narrativas, a estas mujeres se les presupone sistemáticamente la imposibilidad de desarrollar aspiraciones relacionadas con la maternidad o la sexualidad, lo cual implica una violencia sobre las mismas que se ejerce a través de dispositivos censores.

Cuando me quedé embarazada aquí fue un susto general, los médicos, los ginecólogos... Me dicen ¿Cómo lo hacemos? Tranquilo, éste va a salir a la calle como los demás. Ya dan por hecho que yo no voy a ser madre. Y luego hay niños con los mocos colgando, de padres heterosexuales.

Todas estas experiencias de mujeres trabajadoras, racializadas, de avanzada edad y con diversidad funcional que encuentran en el poder disciplinario una auténtica vigilancia, dificultan los procesos de profundización de la democracia participativa en términos de justicia social debido a que, de nuevo, se excluye del campo político a todas aquellas personas que no encajan en una norma comunicativa, corporal, de conducta que se dice universal (MartínezPalacios, Democratizing Participation through Feminism 55) produciéndose exclusiones/expulsiones de la toma de decisiones políticas (Pateman 42).

Mientras, el tercer elemento del marco de los «ámbitos de poder» que permite analizar la interseccionalidad es el (iii) del poder cultural, el cual se refiere a las instituciones sociales y a las prácticas que producen ideas hegemónicas que justifican las desigualdades sociales así como las ideas contra-hegemónicas que critican las relaciones sociales injustas (Collins, The Difference that Power Makes 26). En Zumarraga, se encuentra un ámbito cultural tradicional en el que la comunidad construye el estereotipo de la «mujer cuidadora» como algo natural, relegando las tareas reproductivas y de cuidados a estas mujeres.

Otro de los elementos problematizados dentro del ámbito de poder cultural en Zumarraga se focaliza en las mujeres trabajadoras de religión musulmana que portan el pañuelo/velo islámico, generador de otredad; donde igualmente las mujeres con diversidad funcional encuentran en la silla de ruedas el símbolo de «lo ajeno», donde son interpretadas por la comunidad como algo «fuera de lugar» que impide su integración. Estas lógicas se ejemplifican

Feminismo/s 33, junio 2019, pp. 145-169 
Desvelando opresiones y resistencias de las mujeres en Zumarraga (País Vasco): un análisis interseccional para profundizar la democracia participativa en términos de justicia social

en dos de las participantes, una madre lesbiana y otra nativa islamizada. La primera hace frente a la norma que vincula reproducción con heterosexualidad con el efecto de invisibilizar su opción. La segunda, rompe la norma que relaciona origen y religión, asentada en la identificación de lo musulmán como ajeno, convirtiéndose en una outsider que gracias a sus capitales previos puede enfrentar el estigma, en este caso, asociado a la vestimenta:

De vez en cuando, sí que notas que te señalan. [...] Te dan ganas de decir [...] voy a pasar delante de ti, con mi embarazo, a ver qué pasa iQué a estas alturas de la vida tengamos que estar así! [...] Yo hago mi vida y ya está. Feliz, y no tengo que dar explicaciones a nadie.

Yo no paro a una niña, por ejemplo, y le digo a la madre cómo van vestidas con 13 o 14 años. Porque de esas no se preocupa nadie. Sólo se preocupan de las que nos tapamos demasiado. Yo no voy y le digo ¿Cómo llevas a tu hija así? Y a mí me paran para preguntarme por qué voy así y digo ¡A ti no te tengo que dar explicaciones! Me han parado muchas veces y me han llegado a decir que prefieren que su hija le salga puta antes de que le salga musulmana.

Todos estos fragmentos vivenciales remiten al cuarto elemento del marco de «ámbitos de poder»: el (iv) poder interpersonal, el cual ahonda en una miríada de experiencias que las individuas e individuos tienen dentro de opresiones en interacción (Collins, The Difference that Power Makes 26-27). El clima insolidario estructura las posiciones subordinadas y desiguales de algunas de estas mujeres dentro de su comunidad, con las implicaciones que ello conlleva en las relaciones de poder interpersonal y en cómo estas se entretejen, deviniendo en menor capacidad de las mismas para poder integrarse en la comunidad y establecer relaciones de empatía y reciprocidad entre las mismas y con la comunidad ${ }^{2}$.

\subsection{Las «políticas de comunidad»}

El segundo objetivo es visibilizar las resistencias de mujeres de Zumarraga frente a los sistemas de poder ya desvelados. Se pretende aterrizar los conocimientos de la matriz de dominación y de los «ámbitos de poder» para

2. Precisamente por ello, la estrategia participativa propuesta -asentada en los cuidados comunitarios- buscaría reformular el ámbito de poder interpersonal como primer paso para modificar los otros: el cultural, disciplinario y estructural.

Feminismo/s 33, junio 2019, pp. 145-169 
Desvelando opresiones y resistencias de las mujeres en Zumarraga (País Vasco): un análisis interseccional para profundizar la democracia participativa en términos de justicia social

descender a la idea de comunidad y de cómo estas mujeres tejen sus estrategias de resistencia frente a la interseccionalidad de opresiones que las atraviesa. Para ello se examina cómo la estructura se relaciona con la agencia haciendo uso del tercer marco de Collins en torno a las «políticas de comunidad», al objeto de «conceptualizar el poder para avanzar en la investigación y la práctica interseccional» (Collins, The Difference that Power Makes 22).

Aplicar el marco de las «políticas de comunidad» implica tres principios. El primero parte de la (i) comunidad construida como el vehículo más importante que «une a personas con las instituciones que organizan complejas desigualdades [...] que proporcionan el contexto en donde las personas experimentan relaciones de poder» (Collins, The Difference that Power Makes 27-28) que intersectan de forma dinámica y que son contestadas de dos formas: desde la sumisión y desde la resistencia.

En algunos casos, la solución como sucede con la madre lesbiana pasa por invisibilizar su condición sexual en la vida cotidiana; una respuesta privada presente también en mujeres cuidadoras de personas dependientes. En ambos casos, la respuesta pública se desplaza al tejido social: mientras en el primero de los casos se destaca la creciente potencia de movimientos LGTBI, en el segundo se observa un cierto agotamiento de las experiencias de voluntariado.

Mientras, en otros casos como el de la mujer nativa islamizada la estrategia se aleja de la lógica de la «sumisión» para adentrarse en dinámicas proactivas que hacen evidente la hipocresía de la población local. Una estrategia de resistencia obvia en la valoración de las desigualdades de género, para cuya resolución una de las participantes señala necesario un «trasplante de cerebro». Un cambio de mirada que está en la base de la potencialidad transformadora del feminismo, capaz de construir puentes a la hora de interpretar los cruces de las vulnerabilidades, como refleja una mujer joven nativa:

Molesta que esta señora lleve velo pero no molestan otras cosas machistas de nuestro pueblo. En un bar, en el baño de los tíos había una foto de Brad Pitt con un sombrero. Y en el baño de las chicas una mujer sin piernas y sin cabeza, desnuda, con un pantaloncito corto, en esta pose, y un tío le había dibujado una polla aquí. Qué cosa más bonita ¡Qué respeto! [...] En el feminismo, con las gafas moradas, una vez que ves las cosas no hay vuelta atrás y entonces lo importante es actuar. 
Desvelando opresiones y resistencias de las mujeres en Zumarraga (País Vasco): un análisis interseccional para profundizar la democracia participativa en términos de justicia social

El segundo principio que Collins apunta para desmembrar la idea de comunidad es (ii) comprenderla como lugar en donde hay una fuerte carga de significados que impulsan a las miembras y miembros de la comunidad a proteger y reproducir sus propias comunidades e ignorar e incluso atacar la de otras. En este sentido, la opresión por razón de género ha llevado a gran parte de la comunidad a movilizar sentimientos de necesidad de mayor protección ante la intensificación de la crisis. La doble lógica de sumisión privatización y respuesta politización está presente cuando se considera el cruce del eje de clase con otras dimensiones. Por una parte, algunas mujeres expulsadas del mercado laboral asalariado han experimentado sentimientos de depresión y vergüenza, profundizando y complejizando aún más el eje de opresión de clase. Como reflejan las anteriores citas, estas mujeres han desarrollado estrategias de aceptación/sumisión, muchas de ellas medicándose con antidepresivos para abstraerse y sobrellevar duras situaciones de crisis, mientras que otras de ellas ocultan sus problemas incluso a personas allegadas.

Sin embargo, hay muchas mujeres que también han desarrollado procesos de resistencia, incluso en algunos casos de forma simultánea a los de aceptación. En el ámbito laboral, muchas mujeres están invirtiendo energías y tiempo en la formación continuada para personas adultas para «reciclarse» o «reinventarse». Estos procesos de capacitación tienen implicaciones en términos comunitarios: se construyen espacios donde compartir una misma realidad, trabajándose así la empatía entre ellas; toda vez que se desatan procesos de empoderamiento personales y colectivos que tienen un impacto positivo para la comunidad, siendo en ocasiones capaces de superar desconfianzas previas.

En la jabekuntza eskola (escuela de empoderamiento), hay distintos grupos de mujeres trabajando en empoderamiento y otras muchas cosas, sobre todo porque los grupos tienen una vulnerabilidad determinada. Hay grupos de cuidadoras, grupos de mujeres musulmanas, está la coordinadora feminista a la cual yo pertenezco, mujeres que sufren o han sufrido violencia de género, mujeres mayores... hay un montón de grupos. Si bien es verdad que entre algunos no tienen ni necesidad ni ganas de juntarse con el resto, sí se intenta desde la técnica de igualdad. Y luego nosotras mismas intentamos.

Si se cruzan de forma dinámica los ejes de género y clase con el de raza, este tipo de iniciativas añaden a la pretensión de adquisición de mayores conocimientos el aprendizaje del idioma -principalmente el castellano- y la 
Desvelando opresiones y resistencias de las mujeres en Zumarraga (País Vasco): un análisis interseccional para profundizar la democracia participativa en términos de justicia social

familiarización con tradiciones de la comunidad, lo que dota a las mismas de herramientas para la integración y de sentimientos/autopercepciones de avances en términos de posibilidades/potencialidades de integrarse en la comunidad.

Otro colectivo interesante que emerge del cruce de los ejes de género, clase y edad es el de madres con hijas e hijos en la escuela: el hecho de que la vida comunitaria en Zumarraga refleje una sociedad cada día más multicultural conlleva multiplicidad de niñas y niños de diferentes orígenes, culturas y religiones; erigiéndose la escuela como catalizador para que las madres interactúen. La escuela y la formación en general se construye así como espacio simbólico de correduría y de convivencia principalmente entre madres e hijas e hijos de diversos orígenes.

Tenemos extranjeros estudiando para el graduado de ESO, latinoamericanos, marroquís, senegaleses... en las mismas aulas. Y a mí me parece muy enriquecedor. Se empiezan a conocer, las costumbres y las culturas diferentes. Ahí tenemos que hacer un trabajo importante los profesores. Cuando estás planteando un nuevo tema: Oye y en tú país, ¿Esto cómo lo veis? ¿Qué sistema educativo tenéis? Para conocerse mutuamente, porque me parece que están un poco de espaldas, y ese desconocimiento puede llevar a actitudes un poquito racistas.

Asimismo, las mujeres con diversidad funcional especialmente una de las entrevistadas presentan un discurso con un nivel de politización alto y fuertemente cargado de emocionalidad. Su principal estrategia de resistencia es la capacidad para generar un discurso político eficaz y confrontativo con respecto a visiones estrictas de la idea de comunidad, identificando las estructuras de opresión de forma articulada con la agencia y, por tanto, generando empatía.

Yo si quiero ir al gimnasio del polideportivo de Zumarraga, tengo que pelearme con cuatro o cinco. Porque el gimnasio está bien, pero está para los atletas. Si yo quiero coger unas mancuernas, no llego. Si quiero ponerme unas gomas, necesito ayuda. Y necesito ayuda después de haberles dicho cómo se pueden hacer esos circuitos accesibles. No estoy pidiendo nada, estoy pidiendo que cumplan la ley, y es como que si les tuvieras que rogar.

Finalmente, el tercer principio que Collins señala es la idea de (iii) comunidad como marco para el comportamiento político; donde la representación 
Desvelando opresiones y resistencias de las mujeres en Zumarraga (País Vasco): un análisis interseccional para profundizar la democracia participativa en términos de justicia social

de comunidad está orientada a la acción colectiva. Collins asume que «las colectividades oprimidas a menudo proporcionan más espacio para la individualidad y la humanidad dentro de los confines de sus propias comunidades» (The Difference that Power Makes 28). Esto es, a la hora de trazar sus estrategias de resistencia, las personas oprimidas encuentran en su propio grupo la base sobre la que establecer relaciones que se orientan hacia la acción colectiva para transformar los sistemas de poder que les oprimen, ya que comparten los mismos marcos de diagnóstico, pronóstico y motivación.

Encadenando esta idea de Collins que comprende la comunidad como un marco de comportamiento político, en Zumarraga se observan tendencias a tejer mecanismos de resistencia basados en el sostén mutuo, el tejido de solidaridades, redes de sororidad, autoorganización y estructuración de sus problemáticas de forma colectiva, activándose procesos de politización. Así, diversas mujeres están promoviendo la creación de espacios no segregados ni por motivos de origen ni de género, como el proyecto que una de las entrevistadas intenta poner en marcha, una escuela para padres y madres. Una lógica en la que coinciden todas las personas entrevistadas, quienes consideran necesario poner en marcha estructuras estables que permitan coordinarse a todos los actores locales, sean institucionales o sociales.

\section{HACIA LA PROFUNDIZACIÓN DEMOCRÁTICA Y JUSTICIA SOCIAL}

La aplicación de los tres marcos de Hill Collins -la «matriz de dominación»-, los «ámbitos de poder» y las «políticas de comunidad» permite desarrollar un acercamiento cuyo alcance ayuda a explicar tanto la opresión como las resistencias (Collins, The Difference that Power Makes 22). Así, se aspira al tercero de los objetivos de carácter más normativo: plantear estrategias que desactiven las lógicas de subordinación en Zumarraga y que, por tanto, se erijan como mecanismos de inclusión de estas mujeres en espacios donde han sido históricamente excluidas/expulsadas.

Por ello, es necesario poner el foco en diferentes colectivos de mujeres y construir espacios que sean respetuosos con las problemáticas específicas y diferenciales de las mismas, inclusivos para que su participación presencia y voz sea efectiva y amables para que no se generen situaciones de violencia simbólica. En consecuencia, se debe considerar que la participación está sesgada 
Desvelando opresiones y resistencias de las mujeres en Zumarraga (País Vasco): un análisis interseccional para profundizar la democracia participativa en términos de justicia social

por razones de género, clase y raza (Mansbridge, 56; Young 37-46 y 123-125). Así, las propuestas surgidas en las entrevistas y talleres contemplan la necesidad de realizar un estudio que alumbre los diferentes tipos de violencias que se imponen sobre los colectivos más vulnerables, con el fin de visibilizarlos. Tras «iluminar» realidades, se plantea la necesidad de impulsar campañas de sensibilización donde se impliquen directamente las voces encarnadas de las personas atravesadas por una interseccionalidad de opresiones. Todo ello para diseñar e implementar políticas públicas que reviertan sus situaciones.

Ideas complementadas con demandas como dejar de ubicar en la periferia del municipio los centros destinados a colectivos subordinados, mayor oferta cultural o hacer un llamamiento al Ayuntamiento para la cesión del uso de locales vacíos donde estos colectivos puedan reunirse y encontrar un espacio seguro, un refugio frente a las consecuencias materiales de su opresión. Una vez visibilizadas las experiencias que se encontraban borradas del mapa comunitario, se sugiere una mayor promoción de actividades ya existentes a pie de calle intercambio de comida, mercado de las culturas, además de mayor potenciación del tejido asociativo y la participación ciudadana. Pero la clave de la fase que se inicia tras la elaboración del documento en fase de presentación, está orientada a la creación de estructuras participativas que permitan el diseño y ejecución concertado entre sociedad civil e instituciones públicas de políticas de cuidado comunitario.

Concretamente, en 2019 se ha aprobado por el Ayuntamiento un proyecto destinado a tejer lazos en la comunidad. Este es el resultado de las propuestas sobre cuidados en el que se destaca la dimensión de género como transversal y a la que se debe unir otros elementos como los de clase, etnia y origen. A partir de este diagnostico que trata de resituar a las mujeres más vulnerables racializadas, mayores que viven solas, expulsadas del mercado laboral, cuidadoras en el centro de una comunidad entendida en clave de justicia social, se abre una propuesta de diseño participativo que incorpora a estas mujeres en el centro de una estrategia de vertebración de cuidados que además pretende reactivar las lógicas asociativas que existían en el municipio.

Para ello, el grupo motor que pilote esta estrategia participativa pondrá en marcha un proceso de relatorías para robustecer la empatía entre las personas. A través de la (re)valorización del pasado y el (re)conocimiento del presente, se buscará pensar en clave de futuro, generando potencialidades 
Desvelando opresiones y resistencias de las mujeres en Zumarraga (País Vasco): un análisis interseccional para profundizar la democracia participativa en términos de justicia social

para ir construyendo colectivamente Zumarraga. Estas relatorías se realizarán con el apoyo técnico de la Cooperativa Aradia desde un enfoque interseccional, pensando en abarcar todas las historias que quedan fuera del foco en un modelo industrial y que proceden de colectivos subalternos: una oportunidad para escuchar las otras voces y conocer las estrategias de supervivencia que han tejido con hilos invisibles la vida comunitaria, con el fin de crear vínculos entre los grupos vulnerables. Así, se busca superar los límites del ámbito del poder estructural, cultural y social detectados, además de visibilizar las estrategias de estas comunidades para hacer frente a los cruces de opresiones que las atraviesan.

\section{REFERENCIAS BIBLIOGRÁFICAS}

Archer, Margaret. Realist Social Theory: The Morphogenetic Approach. Cambridge: Cambridge University Press, 1995.

Baca Zinn, Maxine, y Bonnie Thornton Dill. «Theorizing Difference from Multicultural Feminism». Feminist Studies 2.22 (1996): 321-331.

Bilge, Sirma. «Intersectionality Undone». Du Bois Review: Social Science Research on Race 02.10 (2013): 405-424.

Bilge, Sirma, y Patricia Hill Collins. Intersectionality. Cambridge: Polity, 2016. Bordieu, Pierre. La dominación masculina. Barcelona: Anagrama, 2000.

Collins, Patricia Hill. Black Feminist Thought: Knowledge, Consciousness, and the Politics of Empowerment. New York: Routledge, 2000.

- - "The Difference That Power Makes: Intersectionality and Participatory Democracy». Revista de Investigaciones Feministas 1.8 (2017): 19-39.

Crenshaw, Kimberlé. «Demarginalizing the intersection of race and sex: A black feminist critique of antidiscrimination doctrine, feminist theory, feminist theory, and antiracist politics». University of Chicago Legal Forum 3 (1989): 139-167.

Dhamoon, Rita. «Considerations on mainstreaming intersectionality». Political Research Quarterly 1.64 (2010): 230-243.

Dye, Thomas. Understanding Public Policy. Englewood Cliffs NJ: Prentice-Hall, 1984.

Gandarias Goikoetxea, Itziar. «¿Un neologismo a la moda?: Repensar la interseccionalidad como herramienta para la articulación política feminista». Revista de Investigaciones Feministas 8.1 (2017): 73-93. 
Desvelando opresiones y resistencias de las mujeres en Zumarraga (País Vasco): un análisis interseccional para profundizar la democracia participativa en términos de justicia social

Ganuza, Ernesto, Lucrecia Olivari, y Pablo Paño. «La democracia en acción: participación de la ciudadanía en la gestión pública. Metodologías Participativas y Presupuestos Participativos». Democracia Participativa y Presupuestos Participativos. Acercamiento y profundización sobre el debate actual. Ed. Andrés Falck y Pablo Paño. Málaga: Diputación de Málaga, 2011. 149-179.

Guzmán, Maricela y Augusto Renato Pérez. «Las Epistemologías Feministas y la Teoría de Género». Cinta moebio 22 (2005): 112-126.

Hoogwood, Brian y Lewis Gunn. «Policy Analysis: The Dangers of Over Sophistication». Public Administration 54 (1984): 409-424.

Ibarra, Pedro. Democracia relacional. Madrid: CEPC, 2011.

Iglesias, Clara. «Justicia como redistribución, reconocimiento y representación: las reconciliaciones de Nancy Fraser». Investigaciones feministas 3 (2012): 251-269.

Lombardo, Emanuela, y Mieke Verloo. «La interseccionalidad de género con otras desigualdades en la política de la Unión Europea». Revista Española de Ciencia Política 23 (2010): 11-30.

Mansbridge, Jane. «Using/Fighting Power: the Polity». Democracy and difference. Contesting the Boundaries of the Political. Ed. Seyla Behabib. Princeton: Princeton University Press, 1996. 46-66.

Martí, Joel. «La Investigación-Acción-Participativa. Estructura y fases». La investigación social participativa. Coords. Joel Martí, Manuel Montañés y Tomás Rodríguez Villasante. Barcelona: el Viejo Topo, 2002. 79-123.

Martínez-Palacios, Jone. «Democratizing Participation through Feminism. The role of feminist subaltern counterpublics in the expansion of the Basque public sphere». Revista Española de Ciencia Política 43 (2017): 37-59.

-. «¿Qué significa participar? Reflexiones sobre la construcción de las imágenes de la participación». Papers 103.3 (2018): 367-393.

Martínez-Palacios, Jone y Patricia Martínez García. «Presentación». Revista de Investigaciones Feministas 1.8 (2017): 9-17.

Martínez-Salgado, Carolina. «El muestreo en la investigación cualitativa. Principios básicos y algunas controversias». Ciência E Saúde Coletiva (2012): 613-619.

Pateman, Carole. Participation and Democratic Theory. Cambridge: Cambridge University Press, 1970. 
Desvelando opresiones y resistencias de las mujeres en Zumarraga (País Vasco): un análisis interseccional para profundizar la democracia participativa en términos de justicia social

Platero, Raquel (Lucas), Silvia López, y Elin Peterson. «Políticas Públicas». Ciencia Política de género. Coords. Marta Lois y Alba Alonso. Madrid: Akal, 2014. 161-188.

Severs, Eline, Karen Celis, y Silvia Erzeel. «Poder, privilegio y desventaja: teoría interseccional y representación política». Revista de Investigaciones Feministas 1.8 (2017): 41-51.

Squires, Judith. Gender in Political Theory. Oxford: Oxford University Press, 1999. Young, Iris Marion. «Polity and Group Difference: A Critique of the Ideal of Universal Citizenship». Ethics 99 (1989): 250-274.

-. Inclusion and democracy. Oxford: New Ed, 2002.

Walt, Gill. Health Policy. An Introduction to Process of Power. Johannesburg and London: Witwatersrand UP and ZED, 1994.

Zugaza Goienetxea, Uxue. «Claves hacia el empoderamiento de las mujeres gitanas: un análisis desde el punto de vista de la interseccionalidad». Revista de Investigaciones Feministas 8.1 (2017): 203-222. 